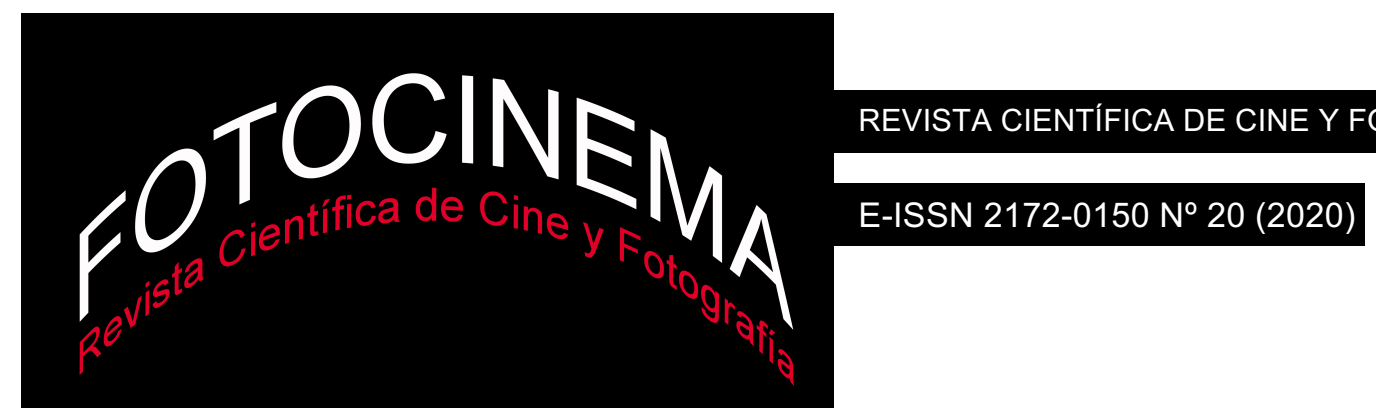

\title{
Match point (Allen, 2005): a propósito del Tom Ripley de Patricia Highsmith
}

\author{
Match Point (Allen, 2005): Regarding Patricia Highsmith's Tom \\ Ripley
}

\author{
María Jesús Cabello Bustos \\ Universidad de Córdoba, España \\ mariajesuscabello@hotmail.com
}

\section{Resumen}

Reconocido como uno de los directores más prolíficos en los últimos 30 años, Woody Allen presentó en 2005 su película Match Point. La característica principal que la define es el comportamiento de su protagonista, Chris Wilton, un tenista retirado del circuito profesional que llega a Londres con grandes aspiraciones. Este personaje arribista y amoral parece surgido de las novelas de Patricia Highsmith, más en concreto de su más famoso personaje, Tom Ripley. Ambos protagonistas comparten nexos comunes: ambición, asesinatos, crímenes sin castigo, facilidad para adaptarse al medio, falta de moralidad... El objetivo del presente artículo es abordar los paralelismos y conexiones entre Match Point y El talento de Mr. Ripley (The talented Mr. Ripley, Highsmith, 1955), tanto en la novela como en sus adaptaciones cinematográficas, centrándonos principalmente en la película que Anthony Minghella presentó en 1999 bajo el título homónimo de la novela de Patricia Highsmith, destacando el uso de la música como recurso narrativo fundamental.

\begin{abstract}
Recognized as one of the most prolific directors in the last 30 years, Woody Allen presented his movie Match Point in 2005. The main characteristic that defines it is the behavior of its protagonist, Chris Wilton, a retired professional tennis player who arrives in London with great aspirations. This upstart and amoral character seems to have emerged from the novels of Patricia Highsmith, more specifically from her most famous character, Tom Ripley. Both protagonists share common links: ambition, murders, crimes without punishment, easy to adapt to the environment, lack of morality... The aim of this article is to address the parallels and connections between Match Point and The talented Mr. Ripley (Highsmith, 1955), both in the novel and in his film adaptations, focusing mainly on the film that Anthony Minghella presented in 1999 under the homonymous title of the novel by Patricia Highsmith, highlighting the use of music as a fundamental narrative resource.
\end{abstract}

Palabras clave:

Intertextualidad; música preexistente; Woody Allen; Patricia Highsmith; Anthony Minghella.

Keywords:

Intertextuality; Preexisting Music; Woody Allen; Patricia Highsmith; Anthony Minghella. 


\section{Introducción}

En 1955 se publicó la cuarta novela de Patricia Highsmith (1921-1995), El talento de Mr. Ripley (también publicada en España como A pleno sol), la primera sobre su personaje más famoso y fascinante, el amoral Tom Ripley. Con esta novela Patricia Highsmith inició una saga a la que le seguirían cuatro títulos más: La máscara de Ripley, El juego de Ripley -también publicada en España como El amigo americano-, Tras los pasos de Ripley y Ripley en peligro. Con este personaje, la autora inventó un nuevo género mezclando la novela negra y la policíaca e introduciéndonos en la psique del protagonista, haciendo partícipe al lector del punto de vista de este carismático antihéroe psicópata. Al igual que ocurre con Chris Wilton -el protagonista de Match Point-, Tom Ripley es descrito, tanto en las novelas originales como en las distintas adaptaciones cinematográficas, como un personaje de orígenes humildes que al descubrir las comodidades que aporta una vida adinerada, hará todo lo necesario por permanecer en ella.

La trama nos narra la historia de Tom Ripley, un estafador y oportunista al que un millonario le propone hacer un viaje a Italia con el objetivo de persuadir a su hijo para que éste regrese a Norteamérica y se encargue del negocio familiar. Tom Ripley acepta la oferta, se embarca rumbo a Italia con todos los gastos pagados esperando tener éxito en su misión, que será correspondido con un buen montante económico. Al llegar a Mongibello, un pueblo imaginario en la costa napolitana, se dará a conocer ante Dickie Greenleaf y ahí comenzará a ver lo distinta que es la vida de Dickie de la que él llevaba en Nueva York. Esa nueva vida le cautivará hasta el punto que decide permanecer en ella para siempre, no importando el precio que hubiese que pagar por ello.

Tanto el protagonista de El talento de Mr. Ripley como el de Match Point, tendrán que llevar a cabo más de un asesinato para salvaguardar sus objetivos y ambos quedarán impunes de ellos. Tanto uno como otro planifican sus crímenes fríamente. En la película de Minghella se muestra impulsivo, una reacción al rechazo de Dickie, en cambio, en la novela queda 
bien claro que ese deseo de matar a Dickie y la idea de hacerse pasar por él es anterior al viaje en barca:

Clavó su mirada en los párpados de Dickie, sintiendo que en su interior hervía una mezcla de odio, afecto, impaciencia y frustración, impidiéndole respirar libremente. Sintió deseos de matar a Dickie. No era la primera vez que pensaba en ello. Antes, una o dos veces, lo había pensado impulsivamente, dejándose llevar por la ira o por algún chasco, pero luego, a los pocos instantes, el impulso desaparecía dejándole avergonzado. Pero ahora pensó en ello durante todo un minuto, dos minutos [...] Tom se dijo que si le mataba durante aquel viaje, le bastaría con decir que había sido víctima de un accidente. De pronto, se le ocurrió una idea brillante: hacerse pasar por Dickie Greenleaf. Era capaz de hacer todo cuanto hacía Dickie. (Highsmith, 1993, p. 103-104).

Como lo definió la propia Patricia Highsmith"1 (Wilson, 2010) : "I think in certain areas he could be called psychotic... a bit sick in certain areas. But I would not call him insane because his actions are rational... He's not so psychopathic that he has to kill somebody. I consider him a rather civilised person who now kills when he absolutely has to. He kills reluctantly.

$\mathrm{Al}$ igual que Chris, también cometerá un asesinato colateral, en este caso el de Freddie Miles, al sospechar que Tom Ripley estaba envuelto en la desaparición de Dickie. En la película de Minghella ocurre un tercer asesinato que no sucede en la novela, el de su amigo Peter Smith-Kingsley. Asesinato también colateral para ocultar su propia identidad y poder seguir suplantando la personalidad de Dickie. La singularidad de este asesinato en la película es que se muestra a Peter como la persona de la que está enamorada Tom y aun así decide asesinarla para preservar su nueva vida en la alta sociedad, exactamente igual que Chris cuando asesina a Nola Rice.

La primera novela sobre Tom Ripley fue llevada al cine por René Clement bajo el título A pleno sol (Plein soleil, 1960), película que sirvió para

\footnotetext{
${ }^{1}$ A la pregunta de si ella considera a Ripley un enfermo, Patricia Highsmith responde "Creo que en ciertos aspectos podría ser calificado de psicótico... un poco enfermo en ciertos aspectos. Pero no lo llamaría demente porque sus actos son racionales... No es un psicópata que tiene que matar a alguien. Lo considero más bien una persona civilizada que ahora asesina porque tiene que hacerlo. Asesina a regañadientes" (Traducción propia)
} 
catapultar a la fama a Alain Delon en el personaje principal, acompañado por Marie Laforêt como Marge y Maurice Ronet interpretando a Dickie, que en esta adaptación cambió el nombre por el de Philippe. 39 años después, el director Anthony Minghella realizó su propia adaptación, no tan alejada de la novela original como la de Clement, titulada como la novela, El talento de Mr. Ripley (The talented Mr. Ripley, 1999) donde reunió a un elenco de grandes actores en su plenitud, con Matt Damon interpretando a Tom Ripley, Jude Law como Dickie Greenleaf, Gwyneth Paltrow como Marge, Philip Seymour Hoffman como Freddie Miles, Cater Blanchett como Meredith Logue y Jack Davenport como Peter Smith-Kingsley.

El aspecto principal de la novela y de sus adaptaciones cinematográficas es que Tom Ripley -al igual que Chris Wilton- es un arribista al que no le importa el medio para conseguir sus objetivos, lo que le hace sacrificar todo para vencer los obstáculos llegando al asesinato. Esto ocurre con Dickie y con Freddie y está muy cerca de ocurrir con Marge. Finalmente reniega de esta última idea autoconvenciéndose de que él no es un asesino, justificando que ambos homicidios fueron cometidos por no encontrar mejor alternativa:

[...] el recordarse a sí mismo de pie ante Marge, con el zapato en la mano e imaginándose todo aquello de un modo frío y metódico. Y el hecho de que hubiese sido la tercera vez. Las otras dos veces eran hechos, no frutos de su imaginación. Podía decirse que no había querido hacerlo, pero lo había hecho, esa era la verdad. No quería ser un asesino. A veces llegaba a olvidarse por completo de que había asesinado. Pero a veces, como le estaba sucediendo en aquellos momentos, le resultaba imposible olvidar. (Highsmith, 1993, p. 251).

Esta necesidad de Tom Ripley por anteponer sus prioridades a la propia existencia de otras personas es similar a lo que hace Chris en Match Point. Tom lo justifica negándose a llamarse asesino y alegando que todo tiene sentido en la cabeza de un asesino -un asesino no se considera a sí mismo una mala persona-, mientras Chris se justifica en que hay que solucionar las crisis de la mejor forma posible -para él- y llamando daños colaterales a las muertes de la señora Eastby y de su propio hijo nonato. 
Las obras que estamos referenciando, tanto El talento de Mr. Ripley y sus adaptaciones cinematográficas como Match Point, tienen la particularidad de generar en el espectador empatía por el asesino, ya que éstas están planteadas desde el punto de vista siniestro, haciendo que lo sucedido en la trama tenga condición de normalidad y el espectador se sienta identificado aceptando e incluso compartiendo la conducta de los asesinos. Como plantea Sigmund Freud en su ensayo Lo siniestro (Obras completas, 1919), la realidad donde se ejecuta una obra no tiene que tener un aspecto siniestro, sino de total normalidad, aunque éste sea originalmente siniestro. Al tener ese carácter normal y sugerir realidad, hace que el lector o espectador no considere estar visualizando algo aberrante, sino algo cotidiano y común y así acepte a los personajes y sus actos como un individuo integrado del conjunto real.

No debemos obviar que, si bien tanto A pleno sol como El talento de $\mathrm{Mr}$. Ripley son plenas adaptaciones de la novela de Highsmith y así aparece acreditado en sus títulos de crédito, Match Point no figura como una adaptación de ningún libro y así fue presentada su candidatura en los premios oscar de 2006 al "Mejor guion original", categoría en la que fue nominada. Si tenemos en cuenta la clasificación de adaptaciones literarias al cine que utiliza Sánchez Noriega (2000) quizás podríamos tratar Match Point como una adaptación libre (p.65-67) de la novela de Highsmith, aunque lo que realmente creemos es que Allen ha unificado varias fuentes para componer su película. En este artículo nos centraremos exclusivamente en el estudio con la novela de Highsmith y sus adaptaciones cinematográficas.

\section{Capacidad de adecuación en el entorno como fuente de promoción social}

Los protagonistas Chris Wilton y Tom Ripley destacan por su alta capacidad de adaptación al medio en el que se encuentran. Nada más comenzar Match Point recordamos que Chris aparece leyendo Crimen y Castigo de Dostoievski y la guía de Cambridge para su mejor comprensión (The 
Cambridge companion to Dostoievski, 2002). Este hecho tiene una doble interpretación; por un lado, se nos muestra cómo Chris busca futuros temas de conversación con personajes de la alta sociedad londinense -como más adelante ocurrirá con el padre de Chloe y Tom- y, por otro lado, le servirá de fuente de inspiración para planificar el asesinato de su amante. De ahí que haya buscado trabajo en uno de los clubes de tenis más prestigiosos de la ciudad. Esta será su manera de establecer contacto con la alta sociedad. No queda reflejado en la película si su afición por la ópera es otra planificación en armonía con los gustos de la alta sociedad o si ésta ya la tenía anteriormente.

En la película de Anthony Minguella podemos observar cómo Tom Ripley aprende todo lo posible sobre jazz antes de viajar a Italia que le sirva para establecer una conexión con Dickie simulando un gusto común. Más tarde vemos cómo Tom Ripley comienza a vestir como Dickie e incluso imita perfectamente su voz, talento innato en él que ya confiesa desde su llegada a Italia cuando define su mejor talento como "falsificar firmas, contar mentiras y prácticamente imito a cualquiera”. El tono informal de la situación hace que el espectador no preste atención a esa autodefinición ni le dé importancia, al igual que ocurre con su interlocutor en la película, Dickie Greenleaf. A medida que avanza la película, el espectador irá descubriendo que es muy cierto que tiene esos tres talentos, además del de ser meticuloso, observador y analizador.

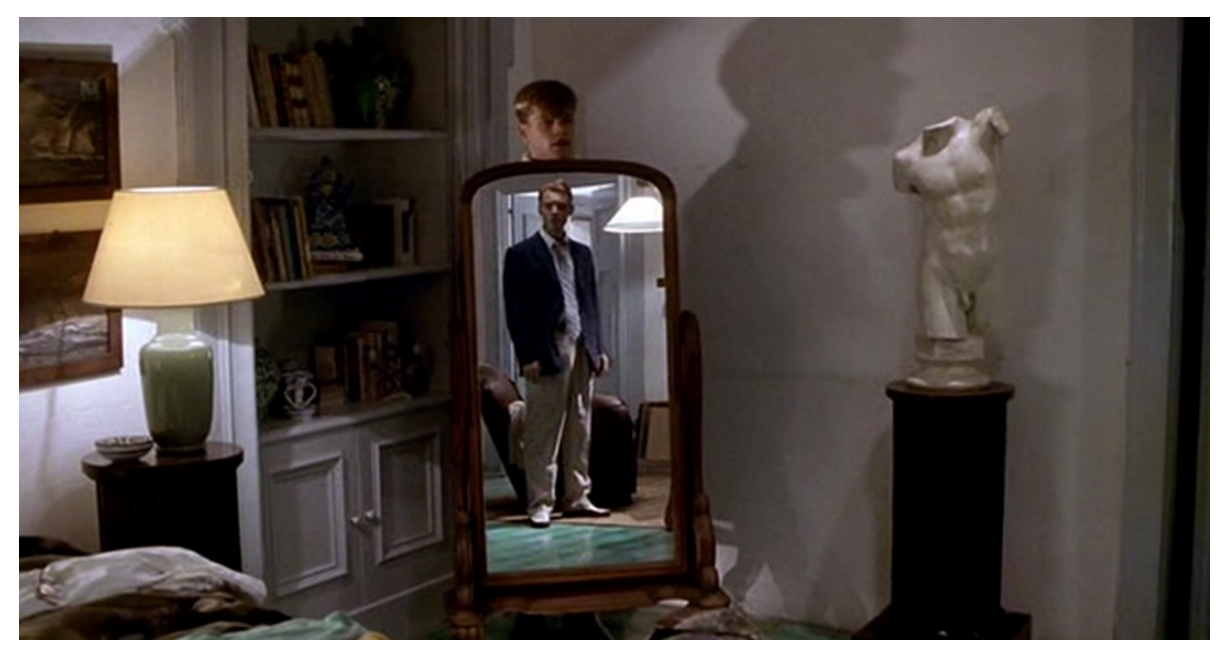

F1. Anthony Minghella, El talento de Mr. Ripley, 1999 
La escena en la que Tom Ripley se prueba la ropa de Dickie (véase F1) mientras imita su voz frente al espejo está perfectamente representada en las adaptaciones de Clement y Minghella, narrándola tal como Patricia Highsmith la describe en su novela. Tom es un perfecto imitador de voces y utilizará su habilidad para suplantar a Dickie una vez lo haya asesinado.

Respecto a Chris, conforme estrecha su relación con la familia Hewett, va adaptándose a ese estilo de vida. Su modelo a seguir es Tom Hewett, el hermano de Nola. Al principio de la película vemos a Chris en un restaurante solo cenando un bocadillo con una Coca-Cola. Más tarde, en los inicios de su relación con Chloe, pide pollo asado en un restaurante de lujo, hecho que provoca la reprobación de su futura prometida y cuñado. Conforme avanza su periodo de adaptación vemos cómo incluso comparte el gusto enológico de Tom:

- Chloe: Abriré una de esas botellas de vino que te compré

- Chris: Ah, el Puligny Montrachet. No lo conocía hasta que Tom lo pidió. Ahora me he hecho adicto. (Allen, 2005).

En este mismo sentido, acepta un trabajo en una de las empresas de la familia Hewett. Cambia su vocación por el tenis -aquello a lo que había dedicado su vida- por gestionar activos en bolsa, un trabajo de oficina igual al de su futuro cuñado Tom. En otra escena lo vemos en Chelsea, uno de los barrios más distinguidos de Londres, donde se encuentra con Nola cuando sale de una tienda Ralph Lauren, comentando que estaba buscando un jersey similar a uno de Tom.

Es reseñable también la posterior escena cuando vuelven a la casa de campo. En esa escena podemos ver cómo Chris viste exactamente igual que Tom y Alec, el padre de Chloe. Todos llevan el mismo tipo de camisa a cuadros y chaleco marrón. Como ya advirtió Nola a Chris justo en la escena anterior, él será convertido en uno más de la familia:

- Nola: ¿̇y qué tal tú y Chloe?

- Chris: Es un encanto

- Nola: Mmm... es un encanto. Y quiere casarse contigo. 
- Chris: No creo que su madre lo aprobara tampoco.

- Nola: No, no, es distinto. Yo no trago a Eleanor y lo sabe, pero a ti... te preparan para el papel. Ya lo verás (Allen, 2005).

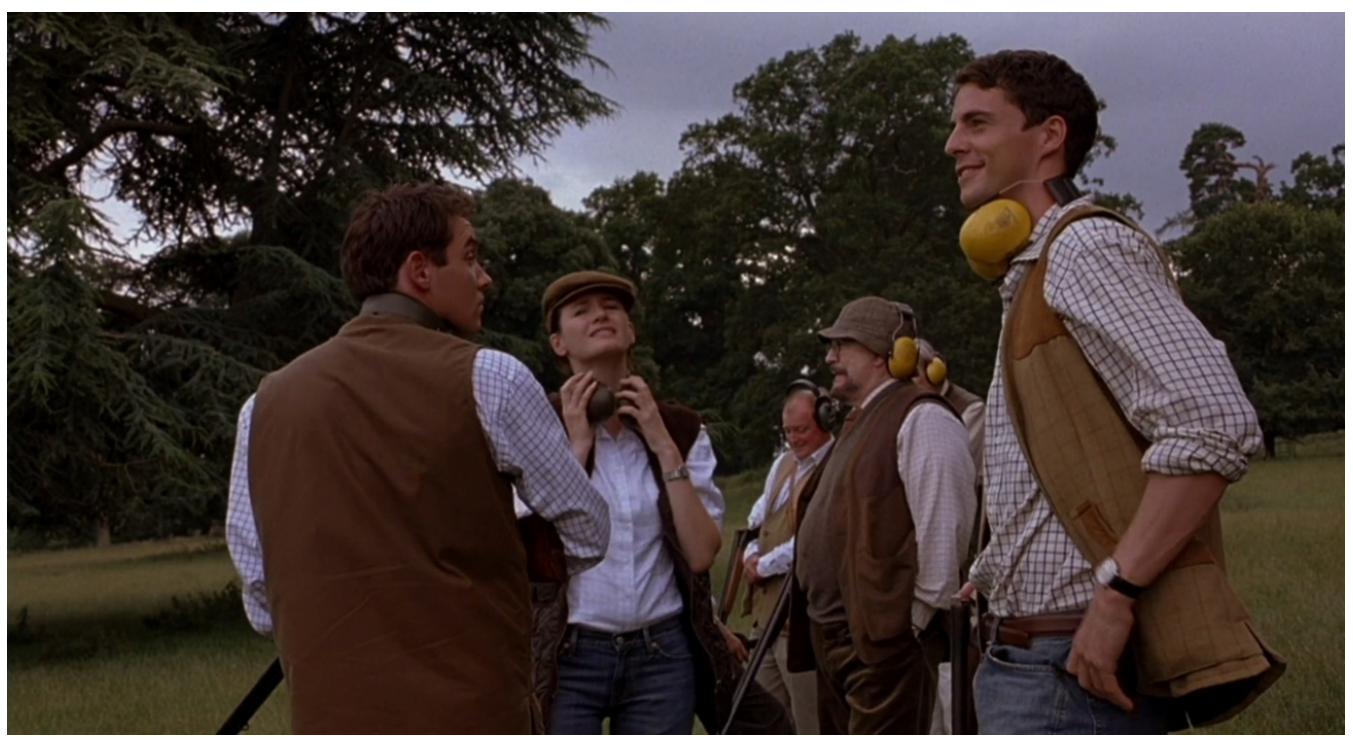

F2. Woody Allen, Match Point, 2005

\section{Utilización de ópera en la diégesis}

En Match Point la asistencia de los protagonistas a las distintas óperas diegéticas tienen una conexión muy importante con la propia trama de la película. Así, cuando los protagonistas acuden al Covent Garden a ver $L a$ traviata y escuchan Un di, felice, eterea, se muestra a Chloe mirando a Chris, referenciando el enamoramiento como un flechazo a primera vista, al igual que está sucediendo en ese momento en la ópera. Otro caso ocurre cuando acuden a ver Guillermo Tell donde los únicos versos escuchados son "Io non so se avrommi gloria, ma la sorte io vo' tentar. Vieni, andiam: fia l'empio estinto"2 mostrando claramente que Chris ya ha decidido la resolución de su relación con Nola. En la película de Minghella también existe este vínculo entre ópera y film. Justo en el ecuador de la película, después de haber cometido los dos asesinatos, Tom es invitado por Meredith Logue, el personaje interpretado por Cate Blanchett, a una función de ópera donde se

2 Traducción: "Yo no sé si obtendré gloria, pero la suerte voy a tentar. Ven, vamos: iMuera el tirano!” 
representará la obra Eugene Onegin (Op. 24, 1879) de Piotr Ilich Tchaikovski, basada en la novela en verso homónima del escritor ruso Alexander Pushkin, publicada en 1831, con libreto escrito por Konstatín Shilovski y por el hermano del compositor, Modest Tchaikovski.

El momento de la ópera que el director nos muestra en pantalla es el conocido como "Aria de Lenski", donde el protagonista, Eugene, se bate en duelo con su mejor y único amigo, Lenski, a consecuencia de este malentendido. A pesar de ser reacios los dos a seguir adelante, la presión de perder el honor es superior y finalmente se produce el duelo. Eugene dispara y Lenski muere. En la película, la escena no se representa completa, obviando la parte donde Eugene y Lenski cantan a dueto el arrepentimiento mutuo a batirse, mostrándose sólo los últimos versos del "Aria de Lenski” y pasando a la escena final del duelo.

En la película, esta escena se representa con una gran carga emotiva para Tom Ripley. Después de terminar Lenski de cantar su aria comienza el duelo, cogen sus respectivas armas y se distancian lo estimado. Cuando se giran, se muestra a Eugene levantando el arma hacia Lenski; el director alterna en la pantalla planos de Eugene apuntando con el arma y de la cámara acercándose con un travelling hacia Tom Ripley al ritmo de la música orquestal donde se identifica a Tom con el personaje de Eugene. El aria de Lenski termina con una melodía cantábile del barítono que termina en $\mathrm{Si}$ menor y que contrasta con el inicio rítmico de Zaretsky dando la orden de comenzar el duelo que modula a La Mayor. La música, principalmente a cargo de la sección de cuerda, gana en intensidad armónica y dinámica mediante un crescendo a tempo allegro, incrementando la tensión. En este fragmento se producen una serie de cambios musicalmente hablando: se pasa de una sección melódica a rítmica, se cambia de tonalidad y modalidad, hay un cambio de textura que pasa de notas largas a rápidas así como un cambio dinámico de pianissimo a forte. Todo ello genera en el espectador la ansiedad que requiere el momento del disparo del duelo. 


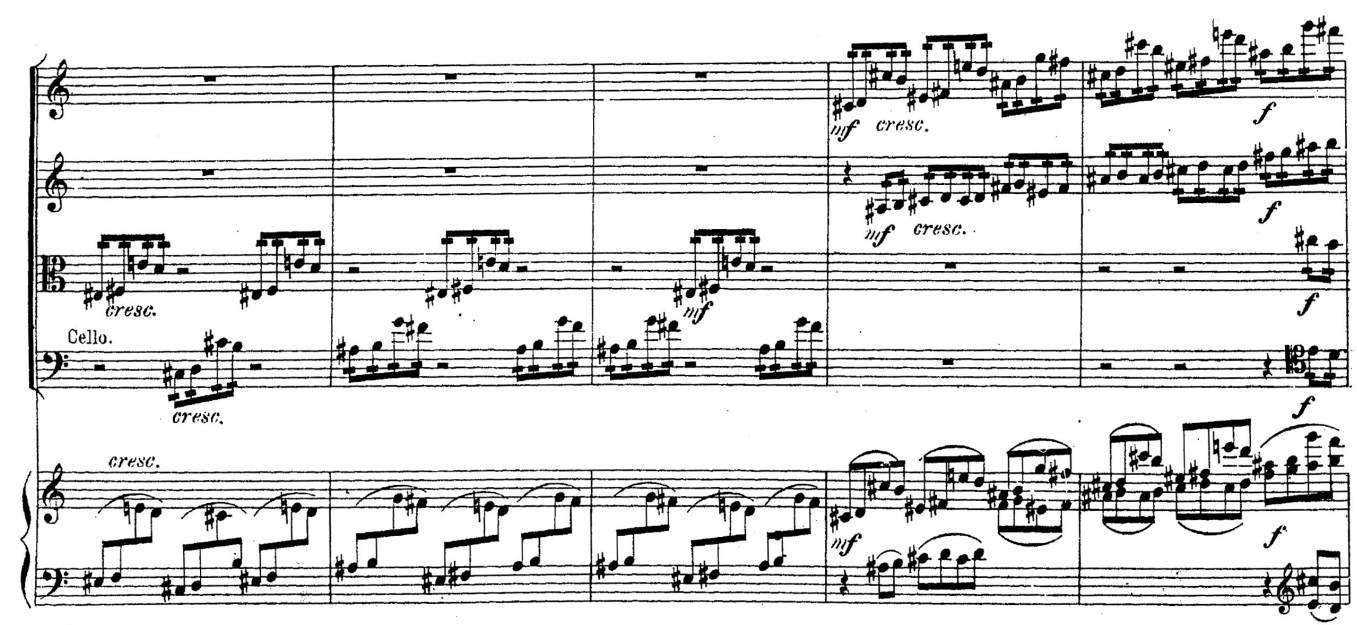

F3. Tchaikovsky, Eugene Onegin, 1831

Mientras la música aumenta en ansiedad dramática, la cámara se aproxima para hacer un primer plano de Tom, al que el sonido del disparo le hace estremecer, creando un momento de gran intensidad y angustia en el personaje, lo que le hace brotar una lágrima de arrepentimiento recordando a su amigo asesinado. Igual que Tom hizo con Dickie, Eugene asesina a su mejor amigo y sufre terriblemente tras haberlo hecho. Similar sufrimiento adolece Chris Wilton tras asesinar -a causa de su ambición- a la persona que más deseaba.

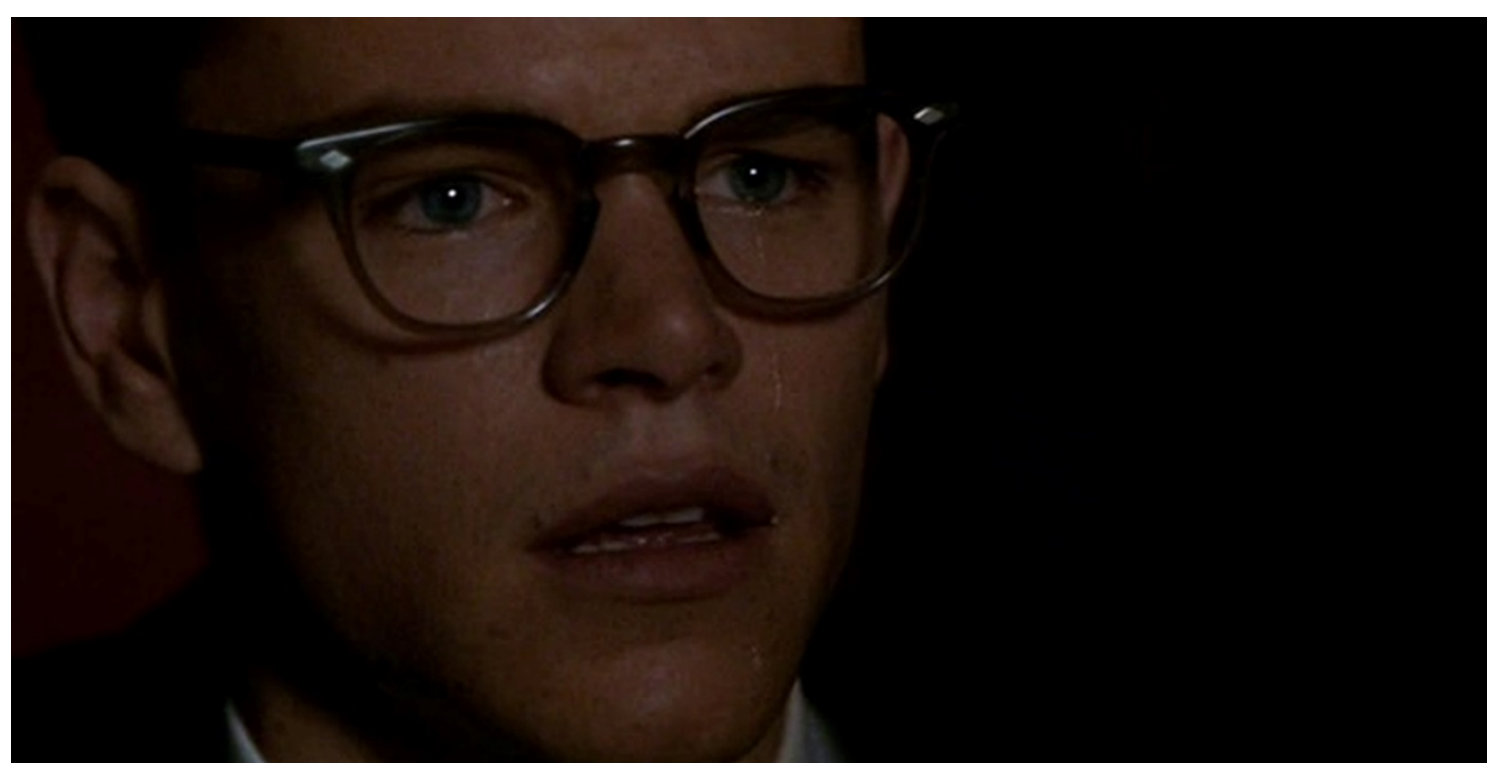

F4. Anthony Minguella, El talento de Mr. Ripley, 1999

Así mismo, el final de la ópera Eugene Onegin concuerda con el destino final de Tom Ripley -y, a su vez, de Chris Wilton, como analizaremos con detalle 
más adelante-. Eugene, años después, se reencuentra con Tatiana en San Petersburgo, a la cual le declara su amor incondicional y ella lo rechaza. Finalmente, él se queda solo cuando Tatiana abandona el escenario pronunciando las que serán las últimas palabras de la representación: “iHumillación! iDolor! iOh, qué miserable destino!”. Ese triste destino solitario es el que comparten nuestros protagonistas.

\section{Falta de moralidad como nexo común}

Durante los créditos iniciales de El talento de Mr. Ripley, en la formación del título, se muestran una serie de adjetivos que definen la personalidad del protagonista. En sólo tres segundos los adjetivos que definen al protagonista cambia hasta en 19 ocasiones. El último de estos es "talented", que ha sido traducido al castellano como "talento", a pesar de que la traducción literal más adecuada sería "talentoso", ya que, como el mismo personaje indica, él tiene varios talentos, no solo uno.
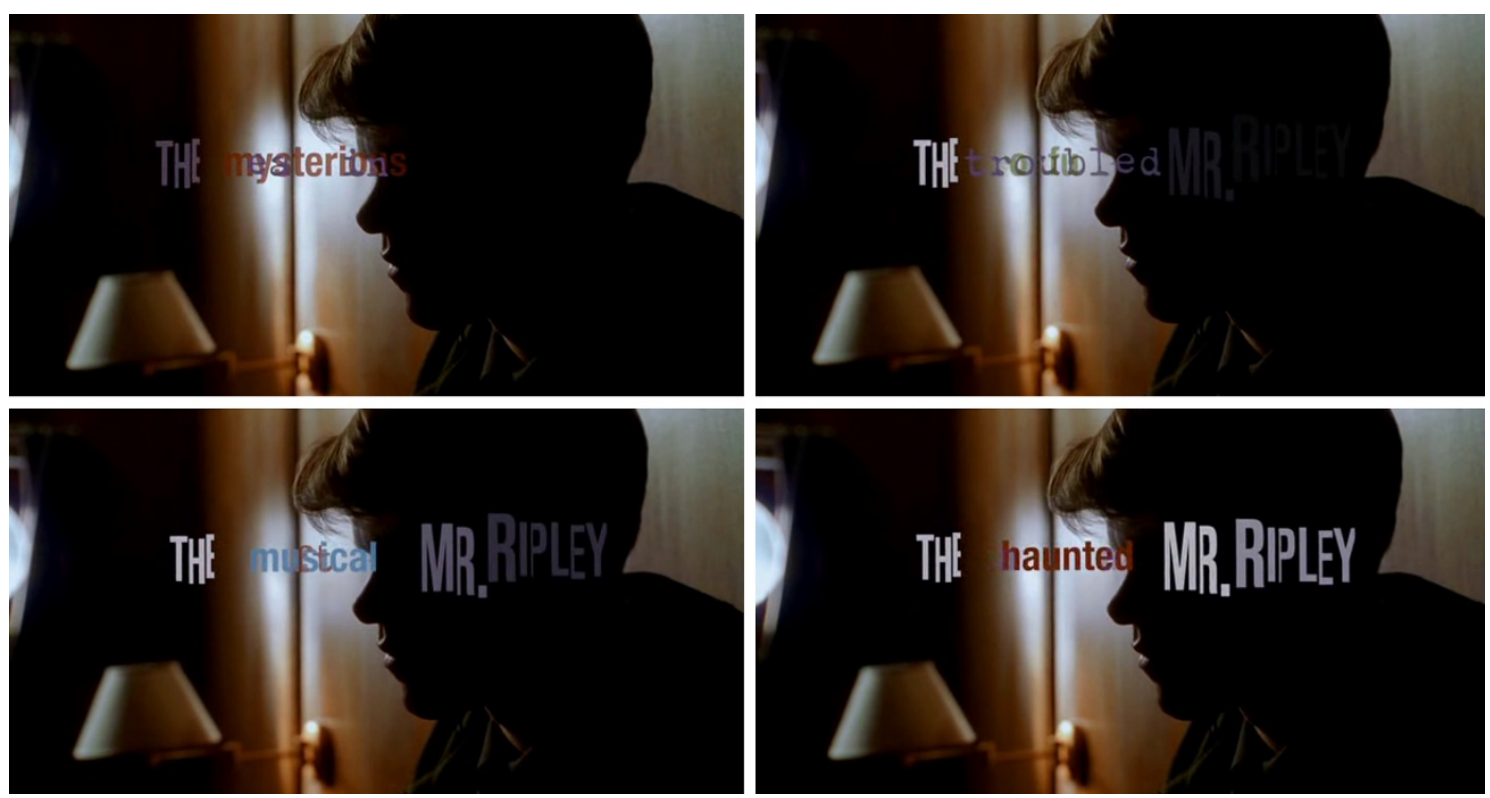

F5. Anthony Minguella, El talento de Mr. Ripley, 1999

Las palabras utilizadas en esta secuencia son: "innocent, mysterious, yearning, secretive, sad, lonely, troubled, confused, loving, musical, gifted, intelligent, beautiful, tender, sensitive, haunted, passionate y talented”, que podemos traducir como inocente, misterioso, ansioso, reservado, triste, 
solitario, preocupado, confuso, amoroso, musical, dotado, inteligente, hermoso, tierno, sensible, obsesionado, apasionado y talentoso. Además de todos estos adjetivos iniciales debemos añadir aquellos con los que el propio protagonista se autodefine: falsificador, mentiroso e imitador, así como los nuevos que va desarrollando a lo largo de la trama: asesino, ambicioso, vanidoso, codicioso y amoral.

A medida que avanza la trama en ambas películas, Tom Ripley y Chris Wilton, dos personajes igual de faltos de moralidad, concluyen que deben llegar al asesinato para conseguir sus ambicionadas metas, que no son otras que ser como los personajes a los que idolatran. En el caso de Tom Ripley, su objetivo no es imitar el modo de vida de Dickie sino suplantarlo y llegar a ser el propio Dickie. En el caso de Chris, su objetivo es tener un rol de vida similar al de su cuñado, Tom Hewett y, por suerte para éste, no tiene que transgredir la moralidad con él, es suficiente con casarse con su hermana. El principal problema ocurre cuando Chris busca la pasión y el amor fuera del matrimonio, ya que éste para él sólo ha sido una herramienta para escalar socialmente, un matrimonio de conveniencia. La relación con su amante se desestabiliza cuando ésta se queda embarazada y él no tiene escrúpulos ni ningún atisbo de moralidad en quitarle la vida asesinándola.

\section{Culpabilidad y arrepentimiento mostrados a través de la música}

Hemos definido a nuestros dos protagonistas, Chris Wilton y Tom Ripley, como dos personas amorales, que cometen asesinatos porque sus mentiras y decisiones llegan a tal magnitud que contemplan el asesinato como la única alternativa posible para permanecer en su nuevo status social. Su propia conciencia se encarga de almacenar esos actos y poder continuar con su vida. Así, en la escena donde Chris cree ver los fantasmas de Nola y la señora Eastby, su confesión es clara al respecto: "Chris: Lo correcto sería ser descubierto y castigado. Al menos habría una mínima señal de justicia. Una mínima cantidad de esperanza de un posible sentido” (Allen, 2005) 
El arrepentimiento de Chris se vislumbra también en la escena donde lanza las joyas al río. La música de la ópera Macbeth en forma diegética interior subjetiva, equipara a Chris con Macduff mientras canta O figli, o figli miei (Oh hijos, oh hijos míos) culpándose de su muerte tras haber huido de Escocia dejando a su familia en el castillo sin su protección.

En El talento de Mr. Ripley de Minghella, Tom Ripley y Peter Smith-Kingsley conversan sobre el asesinato de Freddie. Peter piensa que Dickie es el asesino de Freddie, ya que la policía ha encontrado una carta de Dickie autoinculpándose. Dicha carta ha sido escrita realmente por Tom. Mientras Peter se está refiriendo a Dickie como el asesino, Tom está hablando sobre sí mismo indirectamente.

- Peter: No crees que la escribiera, ¿verdad? La carta de Dickie, ¿te la crees?

- Tom: Ya no sé qué creer.

- Peter: ¿Te imaginas cómo debía de sentirse si mató a Freddie, despertándose mañana tras mañana, y seguir fingiendo? ¿̇cómo puedes continuar siendo la persona, beberte el café...?

- Tom: Hagas lo que hagas, y no importa lo terrible ni doloroso que sea, todo tiene sentido en tu cabeza. No conozco a nadie que se considere una mala persona.

- Peter: Lo sé, pero aun así tienes remordimientos. Has matado a alguien.

- Tom: Sencillamente coges el pasado y lo guardas en una habitación, en el sótano. Cierras la puerta y no entras más. Eso hago yo.

- Peter: Sí, claro. Pero seguramente en mi caso sería todo un edificio.

$-\quad[\ldots]$

- Tom: Si existiera una goma de borrar gigante lo borraría todo, empezando por mí mismo (Minghella, 1999).

En esta escena nos encontramos a Tom Ripley sentado al piano en la casa de Peter Smith-Kingsley tocando una reducción para piano del Stabat Mater $R V$ 621 (1727) de Antonio Vivaldi. La última frase de este diálogo conecta con el principio de la película, al ser estas las palabras con las que -voz en off mediante- comienza la narración de esta historia: "Si pudiera volver atrás, si 
pudiera borrarlo todo, empezando por mí mismo, empezando por una americana prestada”. Estas líneas son acompañadas por otra reducción para piano, la de la canción Lullaby for Cain (Canción de cuna para Caín), que la antecede desde el primer fotograma de la película. Esta canción, con letra compuesta por el propio director de la película, Anthony Minghella y música del compositor Gabriel Yared, comienza siendo extradiegética y tras la voz en off de Tom Ripley se convierte en diegética, esta vez interpretada por el propio Tom Ripley al piano y su amiga Fran, una cantante soprano, interpretada por Gretchen Egolf.

La letra de la canción hace referencia a los hermanos Caín y Abel3, con los que crea un paralelismo con Tom Ripley y Dickie Greenleaf, respectivamente. Ellos mismos se llaman hermanos durante la película. El propio director de la película lo comenta en una entrevista; al ser preguntando por esta canción en concreto:

It's sung over the opening sequence. I was looking for something that Ripley could be playing at the very beginning of the film, and we were listening to all kinds of arias. In the end it just seemed like it would be more organic if [composer Gabriel Yared] and I could write something together and have it speak, however obliquey, about what the film was about. I've always thought the film had a primal quality that seemed so much like the Cain and Abel story on some level. The man who gets mocked, followed by covetousness and then murder in the desert. All those themes seem to be somewhere, however obliquely, in Ripley. I just imagined what it would be like if Eve was forced to sing a lullaby to the son who murdered her other son. Sinead O'Connor sings it in the film4 4 . (Falsetto, 2013, p. 62).

\footnotetext{
3 Recogida en el Génesis, primer libro del Antiguo Testamento de la Biblia Cristiana

4 Se canta sobre la secuencia de apertura. Estaba buscando algo que Ripley pudiera estar tocando al principio de la película, y estábamos escuchando todo tipo de arias. Al final, parecía que sería más orgánico si [el compositor Gabriel Yared] y yo pudiéramos escribir algo juntos con letra, aunque fuera oblicuamente, acerca de lo que trataba la película. Siempre he pensado que la película tenía una calidad primordial que se parecía mucho a la historia de Caín y Abel en algún nivel. El hombre que se burla, guiado por la codicia y luego asesina en el desierto. Todos esos temas parecen estar en algún lugar, posiblemente en forma oblicua, en Ripley. Imagino cómo sería si Eva se viera obligada a cantarle una canción de cuna al hijo que asesinó a su otro hijo. Sinead O'Connor lo canta en la película (Traducción propia)
} 
Después de introducir al espectador en la película con Lullaby for Cain, el director utilizará variaciones de esta misma melodía en cada escena de especial relevancia en la trama de la película, desde cuando imita la voz del padre de Dickie hasta la escena final donde asesina a Peter, pasando por el momento donde espía la conversación entre Marge y Dickie e imita sus voces frente al espejo o cuando Dickie lo descubre probándose su ropa o cuando se encuentra a Marge en la ópera. En cada escena donde se quiere resaltar el comportamiento de Tom, presentando rasgos de su verdadera identidad, escucharemos esta melodía -o una variación de ella-, principalmente a cargo de instrumentos de percusión que imitan el sonido de una caja de música, como el xilófono o las campanas tubulares. Según Kristen Poluyko, "the song Minghella inserts into the film whenever there is a point to be made about Tom's troubled psychological state"5 (2011, p. 31).

\section{Música como recurso narrativo}

Otro rasgo característico que comparten sendas películas es la utilización de las obras que conforman su banda sonora como una herramienta narrativa importante. Desde el comienzo de ambas películas la música toma un papel determinante; al igual que vemos el papel trágico que presagia Una furtiva lágrima en Match Point, observamos que algo similar ocurre con Lullaby for Cain en El talento de Mr. Ripley. Ambas canciones acompañan los títulos de crédito iniciales y dan paso a la voz en off de los protagonistas.

Michel Chion, en su clasificación de las voces y sonidos audiovisuales definió como sonido interno subjetivo a aquel escuchado internamente por el personaje:

Se llamará sonido interno al que, situado en el presente de la acción, corresponde al interior tanto físico como mental de un personaje: ya sean sus sonidos fisiológicos de respiración, de jadeos y de latidos del corazón (que podrían bautizarse como sonidos internos-objetivos), o sus voces mentales,

\footnotetext{
${ }_{5}^{5}$ Minghella inserta esta canción en la película cada vez que se hace una observación sobre el problemático estado psicológico de Tom (Traducción propia)
} 
sus recuerdos, etc. (que llamaremos internos-subjetivos o internos-mentales) (Chion, 1993, p. 78).

Como indica Táhirih Motazedian en su tesis To key or not to key: A tonal design in film music (2017), sobre la música compuesta por el compositor Gabriel Yared para esta película, "There are not static signpost, but a dynamic network of themes that derive from one another and interact in meaningful ways, developing and evolving according to their function within the narrative"6 (p.52) y continua con "Unlike most films, in which themes are designated for a variety of different characters, places, or plot elements, all of the themes in The talented Mr. Ripley are written solely for Tom, reflecting the various emotional and psychological stages of his experience"7 (p.52). En efecto, podemos definir todas las partituras creadas por Gabriel Yared como música interior subjetiva de Tom Ripley -al igual que ocurre en Match Point con los fragmentos de las óperas cantadas por Enrico Caruso respecto a Chris Wilton-, ya que estos fragmentos están referenciando en todo momento el estado anímico y psicológico de Tom, teniendo muy en cuenta que la historia está contada por el protagonista, ya sea interpretándolo como una narración de éste o una sucesión de flashbacks. Recordemos que la película comienza con la voz en off de Tom Ripley sentado en su camarote con la mirada perdida tras haber asesinado a Peter, arrepintiéndose de los hechos ocurridos.

Destacamos que, de las nueve obras compuestas para esta película, siete de ellas están en re menor, excepto la pieza que escuchamos en la escena en la que Tom llega a Italia que está en el relativo mayor de re menor, es decir, en fa mayor y en la obra Promise que está en mi bemol menor. Evidentemente esto no es una simple casualidad, sino que muestra una clara intención por parte del compositor para provocar en el espectador un determinado

\footnotetext{
${ }^{6}$ No hay leitmotivs estáticos, sino una red dinámica de temas que se derivan unos de otros e interactúan de manera significativa, desarrollándose y evolucionando de acuerdo a su función dentro de la narrativa (Traducción propia)

7 A diferencia de la mayoría de las películas, en los que los temas están diseñados para una variedad de diferentes personajes, lugares o elementos de la trama, todos los temas de $E l$ talento de Mr. Ripley están escritos únicamente para Tom, reflejando las distintas etapas emocionales y psicológicas de su experiencia (Traducción propia)
} 
sentimiento. Martin Chusid ${ }^{8}$ interpreta la tonalidad de re menor como una tonalidad en la que “predominan las emociones más oscuras”. Por otro lado, Lüthy ${ }^{9}$ habla en su tesis sobre la tonalidad en re menor como una tonalidad "relacionada con una única situación dramática: la venganza”.

Por un lado, el hecho de la utilización casi exclusiva del modo menor hace una clara referencia al carácter emocional, trágico y melancólico asociado a este modo, expresando un significado específico que genera en el espectador dichas emociones. Por el otro, en cuanto al uso de una determinada tonalidad, hay numerosos estudios ${ }^{10}$ encaminados a justificar el carácter particular que un compositor busca al elegir una tonalidad específica. En este sentido no es casualidad que Re mayor sea la tonalidad elegida para aquellas obras con carácter festivo o militar o que la tonalidad do menor se utilice para buscar un carácter trágico y apasionado, como podemos apreciar claramente en la obra de Beethoven.

\section{Macbeth. Una intertextualidad compartida}

Definió Genette en su obra Palimpsestos (1989) la intertextualidad, de manera restrictiva, como "una relación de copresencia entre dos o más textos, es decir, eidéticamente y frecuentemente, como la presencia efectiva de un texto en otro" y a ésta la clasificó en varias formas: la cita, el plagio y la alusión. En la forma más habitual, la cita, el texto referido se recoge con las palabras originales y citando su fuente original. En el plagio, sin embargo, el texto se recoge igualmente con las palabras originales pero sin mencionar la fuente o autor y en la forma alusión, se menciona al autor y al texto original sin reproducir fielmente las palabras originales.

Macbeth es una obra de William Shakespeare publicada por primera vez en 1623, conocida como "la obra de la ambición”. Está muy relacionada con

\footnotetext{
8 Véase nota $\mathrm{n}^{0} 10$

9 Véase nota $\mathrm{n}^{\mathrm{O}} 10$

${ }_{10}$ The significance of D Minor in Mozart's Dramatic Music, en Mozart-jahrbuch, 1965/66 (p88-89) de Martin Chusid, Vergleichende Characteristik von c- und d-moll-Werken Bach und Beethoven en Schweizerische Musikzeitung 83, 1943, p1-8 de Ernst Isler o Mozart un die Tonartencharakteristik de Werner Lüthy, Heitz, Estrasburgo, 1931
} 
Match Point: gran ambición del protagonista, oráculos que le predicen su futuro, asesinatos para conseguir su objetivo, así como visiones de los personajes asesinados por el protagonista. Para enfatizarlo, Woody Allen se encargó de crear una relación explícita al incluir en la banda sonora un fragmento de la ópera Macbeth (1847) de Verdi, Oh figli, o figli miei, donde identifica el asesinato de Nola y su hijo nonato con el asesinato ordenado por Macbeth de la familia de MacDuff:

O figli, o figli miei!

da quel tiranno tutti

uccisi voi foste, e insieme con voi

La madre sventurata!...

Ah, fra gli artigli

Di quel tigre io lasciai la madre e i figli?
¡Oh, hijos, oh hijos míos!

Por aquel tirano todos

fuisteis asesinados, $\mathrm{y}$ junto con vosotros,

ivuestra desventurada madre!

Ah, ¿y entre las garras de este tigre fui capaz de dejar a la madre y a los hijos?

Anthony Minghella, en El talento de Mr. Ripley, también se encarga de crear una relación explícita con Macbeth. Cuando la amistad entre Dickie Greenleaf y Tom Ripley está en su momento álgido, Tom le pide a Dickie que copie un párrafo de un libro para analizar su letra y su firma en una postal. El libro que le da no es otro que Macbeth, y el párrafo que le pide que copie es un pensamiento del propio Macbeth: "Stars hide your fires! Let not light see my black and deep desires" ${ }^{11}$.

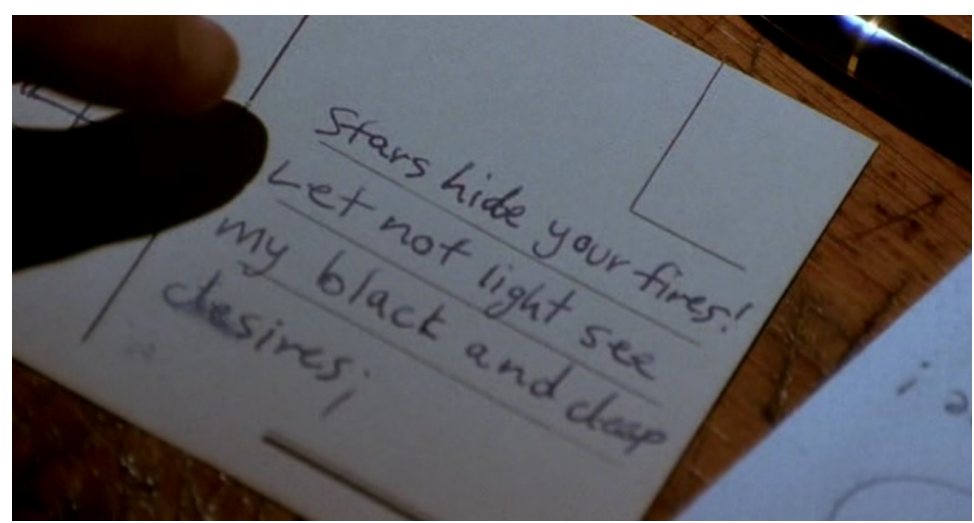

F6. Anthony Minguella, El talento de Mr. Ripley, 1999

\footnotetext{
11 “iEstrellas, ocultad vuestro fuego! Que la luz no revele mis negros y profundos deseos (Traducción propia)
} 
Este pensamiento lo tiene Macbeth al escuchar por boca de su primo, el rey Duncan, que ha nombrado heredero del trono a su hijo Malcolm:

Rey Duncan: Hijos, parientes, duques y vosotros cuyos lugares nos están más próximos, sabed que legaremos nuestro Reino a nuestro hijo mayor, Malcolm, a quien nombramos desde ahora Príncipe de Northumberland: honor que no debe sólo revestirle, sin más compañía, sino que otros signos de nobleza brillarán como estrellas en todos cuantos lo merezcan.

$[\ldots]$

Macbeth (aparte): El Príncipe de Cumberland: éste es un escalón en que debo tropezar, o saltar, pues se me pone por delante. Estrellas, ocultad vuestro fuego: que la luz no revele mis negros y profundos deseos; el ojo se cierre ante la mano; pero sea lo que el ojo teme ver cuando está hecho (Shakespeare, 1980, p. 130).

Los negros y profundos deseos de Ripley son similares a los de Macbeth. Su deseo principal no es ser como Dickie, sino ser el propio Dickie. Desea vivir en su casa, tener su clase social, su poder económico, su ropa y sus joyas. A esto se une un deseo homosexual hacia Dickie, más explícito en la película de Minghella que en la obra de Highsmith, y aspecto totalmente abolido en la adaptación de Clement, donde el objeto de deseo sexual es tener también a Marge, al igual que la tenía Dickie. Este cambio debe ser tenido en cuenta según el contexto social de la época en que se rodó la película, en el año 1960, al igual que la variación del final donde el asesino no queda libre y es detenido por la policía tras descubrirse el cadáver de Dickie Greenleaf.

Esa misma postal volverá a aparecer de nuevo en la película una vez que ya ha asesinado a Dickie. Tom la utiliza para comprobar lo válida que es su imitación de la firma de Dickie. A nuestro protagonista, al igual que a Chris Wilton y a Macbeth, los mueve la ambición y no dejarán que nada se interponga en su camino hacia el éxito. En la película de Minghella se modifica el asesinato de Dickie, donde nos muestra a un Tom que, a pesar de dar muestras de su ambición por suplantar a Dickie, ejecuta el asesinato de manera impulsiva cuando éste le dice que quiere que salga de su vida. En la obra original de Patricia Highsmith y en la película de René Clement no 
sucede así; el asesinato de Dickie es premeditado y planificado previamente por Tom, y encuentra el momento adecuado para cometerlo durante un paseo en barca. Y no solamente comparten el asesinato por ambición, sino que también asesinarán a todo aquel que pueda perjudicarle y hacerle perder sus tan ansiados objetivos. En el caso de Macbeth, al predecir las brujas que su fiel amigo Banquo será padre de reyes, ordena asesinarlo junto a su hijo e igualmente lo ordenará con MacDuff, también tras conocer a través de las brujas que representará un peligro para él "Macbeth, Macbeth, Macbeth: cuidado con MacDuff. Cuídado con el Barón de Fife" (Shakespeare, 1980, p. 166).

Además de la ambición y el asesinato de una persona para suplantar su lugar, Tom Ripley y Macbeth también comparten arrepentimiento. Si bien el arrepentimiento de Macbeth no ocurre hasta una vez asumida su culpa y sentirse víctima de su propio crimen, el arrepentimiento de Tom lo sufre en el mismo momento en que ha ejecutado el asesinato de Dickie, incluso llega a recostarse junto al cuerpo inerte.

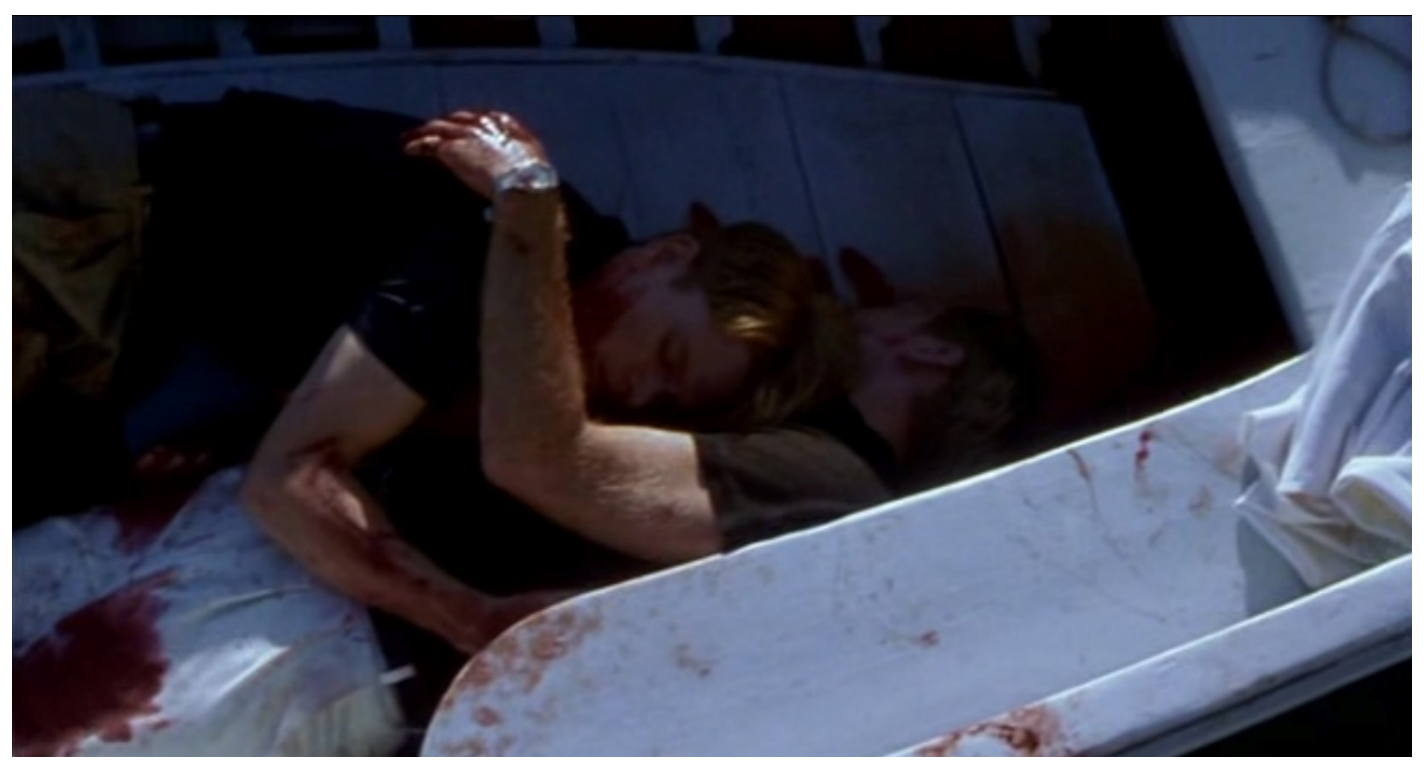

F7. Anthony Minguella, El talento de Mr. Ripley, 1999

El arrepentimiento también se manifiesta tras el asesinato de Peter SmithKingsley. Tom sufre mientras lo asesina y posteriormente, ya en su camarote, quedará pensativo con la mirada perdida. Esta es la escena que se muestra al 
inicio de la película. En cambio, sobre el asesinato de Freddie Miles apenas muestra arrepentimiento:

Se quedó contemplando el largo y pesado cuerpo de Freddie, con el abrigo hecho una pelota debajo del mismo, sin que él, Tom, se atreviera o tuviera fuerzas suficientes para enderezarlo, aunque le molestaba verlo. Una y otra vez, pensaba en lo triste, estúpida, peligrosa e innecesaria que era aquella muerte, y cuán brutalmente injusta para el propio Freddie. Por supuesto, no resultaba imposible odiar a Freddie: un cochino y un egoísta que se había atrevido a despreciar a uno de sus mejores amigos (porque sin duda Dickie era uno de sus mejores amigos) solamente porque le sospechaba culpable de su desviación sexual [...] Bajó la vista hacia Freddie y con voz baja y llena de resentimiento dijo: - Freddie Miles, has sido víctima de tu propia mente retorcida. (Highsmith, 1993, p. 147-148).

\section{Epílogos análogos. Sin la pretendida felicidad}

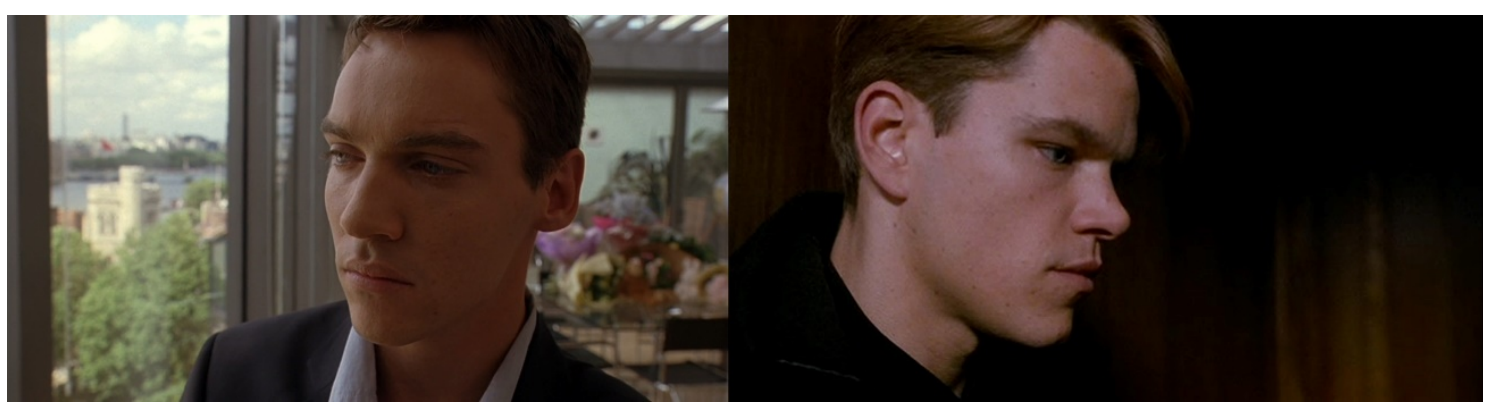

F8. Woody Allen, Match Point, 2005 - Anthony Minguella, El talento de Mr. Ripley, 1999

Nos encontramos con varias similitudes en los finales de Match Point y $E l$ talento de Mr. Ripley. Ambos protagonistas expresan de una manera similar lo que ha ocurrido con sus vidas. Por un lado, tenemos a Chris, quien tras regresar del hospital después del nacimiento de su hijo, no muestra ni un ápice de felicidad mientras su familia política lo está celebra con champagne. $\mathrm{Al}$ contrario, se muestra alejado del resto de personas, mirando a través de la ventana con la mirada perdida y mostrando con su expresión un sentimiento de angustia por haber perdido a quien amaba. Ha quedado libre de castigo, pero el precio a pagar por su ambición le perseguirá siempre. Junto a esa imagen el espectador escuchará por primera vez los últimos versos del aria 
Una furtiva lágrima, de El elixir del amor (1832) de Gaetano Donizetti, interpretada por el tenor Enrico Caruso, en una grabación fechada entre 1904 y 1910.

Cielo! Si può morir!

Di più non chiedo, non chiedo.

Ah, cielo! Si può, Si può morir

Di più non chiedo, non chiedo.

Si può morir, Si può morir d'amor.
¡Cielos! ise puede morir!

Más yo no pido, no pido.

¡Ah Cielos! Se puede, se puede morir!

Más yo no pido, no pido.

Se puede morir, iSe puede morir de amor!

En el caso de Tom Ripley, nos encontramos con el final más terrible de las tres versiones aquí comentadas. Ha embarcado rumbo a Grecia con Peter pretendiendo olvidar lo ocurrido en Italia, buscando la felicidad en un nuevo lugar, pero en el barco también viaja Meredith Loge. Cuando vuelve al camarote de Peter, le propone que se queden allí dentro el resto de la travesía, pero Peter le comenta que lo ha visto con Marge, provocando que Ripley tenga que proteger de nuevo su coartada asesinando a Peter. Nuevamente debe matar a quien ama, al igual que con Dickie. Tras el asesinato, vuelve a su camarote y se queda sentado con la mirada perdida. $\mathrm{Su}$ rostro refleja el dolor por los actos cometidos. De nuevo nos muestra el director a Ripley reflejado en un espejo para simbolizar la dualidad de su personalidad. Además, esta imagen nos remite a la escena inicial de la película, que comenzaba mostrándonos ese mismo primer plano del protagonista con los títulos de crédito superpuestos y la voz over del protagonista: "Si pudiera volver atrás. Si pudiera borrarlo todo, empezando por mí mismo, empezando por una americana prestada” donde deja clara muestra de todo su arrepentimiento por lo ocurrido.

En la versión original, la novela de Highsmith, Tom no muestra ningún arrepentimiento al final, al contrario, es feliz por haber conseguido su objetivo sin ser descubierto por la policía. Cuando llega a su nuevo destino, Creta, finaliza la novela con la respuesta que le da al taxista: "A un hotel, por favor. Al mejor hotel. iAl mejor, al mejor!” (Highsmith, 1993, p. 286). 
En la película $A$ pleno sol nos encontramos con dos finales: el final propio de la película, donde se nos muestra cómo se descubre el cadáver de Dickie y la policía detiene a Tom y, sólo unos minutos antes, el director nos muestra otro final que, debido al contexto social de la época, no pudo implementar: justo en la misma escena donde la policía acude a buscar a Tom, él está tumbado en una hamaca a pleno sol disfrutando de su nueva vida como Dickie -en esta adaptación se han omitido todas las referencias homosexuales de Tom e incluso tiene al final de la película un romance con Marge- y le pide a una camarera que le sirva: "Deme algo de beber. Lo mejor, lo mejor, lo mejor, mejor..." haciendo una clara referencia a la frase con la que termina la novela.

\section{Consideraciones finales}

En este artículo hemos abordado el análisis del personaje Tom Ripley desde el punto de vista asociativo a Chris Wilton, el protagonista de Match Point. Si bien una gran cantidad de análisis que encontramos sobre Match Point nos emplazan a que la obra es una adaptación de Crimen y castigo (Dostoievski, 1866) ${ }^{12}$, creemos haber demostrado con este análisis la influencia de $E l$ talento de Mr. Ripley en ella. Si bien, la secuencia del doble asesinato es una adaptación -más bien, un homenaje- a la obra de Dostoievski. Tras haber revisado el comportamiento de Chris Wilton y Tom Ripley -tanto en la novela original como en las adaptaciones cinematográficas mencionadas- y sus adaptaciones y evolución, constatamos los nexos comunes que enlazan a Match Point con El talento de Mr. Ripley, como la ambición, facilidad de adaptación al medio, amoralidad, ejecución de asesinatos; así como el tratamiento de la música como hilo conductor de la trama. No debemos obviar que el protagonista de Match Point comparte rasgos psicológicos, además de con Tom Ripley, con otros personajes de la literatura, como es el caso de Julen Sorel, protagonista de Rojo y Negro (Stendhal, 1830) o Rodia Raskólnikov, de la ya citada Crimen y castigo.

\footnotetext{
${ }^{12}$ Kuz (2011), Ruiz de Loizaga Martín (2016) o Rivera León (2017) son ejemplos de esta opinión mayoritaria.
} 
Es fundamental el papel que desempeña la música en sendas películas de Minghella y Allen, aunque cada una tiene sus propias particularidades: en la película de Minghella se utiliza música clásica, jazz y música compuesta por Gabriel Yared para crear tres vertientes: la clásica que representa la personalidad original de Tom, un individuo tradicional y organizado; la improvisación propia del jazz, identificado por Dickie, un personaje espontáneo y libre; y por último la música incidental creada por Yared que acompaña los pensamientos y el estado anímico de Tom. En Match Point, únicamente se ha utilizado música preexistente, principalmente fragmentos de ópera decimonónica, utilizados de una manera similar a los creados por Yared: los fragmentos grabados por Caruso acompañan los pensamientos de Chris Wilton durante la trayectoria del film conectando éstos con la trama a través de la música.

Muy significativa es también la asistencia de los protagonistas de ambas películas a representaciones de ópera: en sendos casos se utilizan los fragmentos que están visualizando diegéticamente para dotar a la narrativa de un significado ampliado, capacitando al espectador melómano de un alcance mucho mayor donde la ópera se integra en la narrativa formando un único corpus.

La ambición es otro pilar fundamental en nuestros protagonistas. A través de la inclusión directa de Macbeth tanto en la película de Minghella como en la de Allen, se genera una conexión intertextual con la obra de Shakespeare. La misma ambición que lleva a Macbeth a ejecutar un regicidio para obtener la corona, es la que lleva a Chris y Tom a asesinar a fin de conseguir un status social superior que obtendrán sin importar los daños colaterales ocasionados.

Como hemos podido constatar, la amoralidad y el arrepentimiento son dos nexos comunes entre los protagonistas: su falta de moralidad les permite realizar todo tipo de acciones, llegando a cometer el asesinato de las personas que más aman con el objetivo de conseguir -o proteger- el codiciado status social. El arrepentimiento posterior les frusta ya que no han conseguido obtener la felicidad anhelada a través de sus actos cometidos, 
arrepintiéndose de estos cuando ya no queda otra solución. El cierre de las obras de Allen y Minghella constata este arrepentimiento final, reflejado en la frase con la que comienza la obra del director británico: "Si pudiera volver atrás, si pudiera borrarlo todo”.

\section{Referencias bibliográficas}

Allen, W. (2005). Match Point. Guion cinematográfico. Madrid: Espiral.

Chion, M. (1993). La audiovisión. Introducción a un análisis conjunto de la imagen y del sonido. Barcelona: Paidós.

Falsetto, M. (2013). Anthony Minghella. Interviews. Mississippi: University Press of Mississippi.

Freud, S. (2017). Obras completas. Ebook, Oregan Publishing

Genette, G. (1989). Palimpsestos. La literatura en segundo grado. Madrid: Taurus.

Highsmith, P. (1993). A pleno sol (The talented Mr. Ripley). Barcelona: RBA Editores.

Kuz, M. (2011). Justice and the Western Perception of Dostoievsky: Woody Allen's Crimes and Misdemeanors and Match Point. APSA 2011 Annual Meeting Paper. Recuperado de

https://ssrn.com/abstract=1903053

Minguella, A. (2000). The talented Mr. Ripley: Screenplay. Londres: Methuen Drama.

Motazedian, T. (2017). To key or not to key: Tonal design in film music (Tesis doctoral). New Haven: Universidad de Yale.

Poluyko, K. (2011). Alternative Music: Jazz and the Performative Resignification of Identity in Anthony Minghella's The Talented Mr. Ripley. The Journal of Men's Studies, Vol. 19, No 1, MSP.

Rivera León, L. (2017). ¿Crimen sin castigo? Sobre la primera incursión de Woody Allen en el universo moral de Dostoievski. En Miradas intersubjectivas en la filosofía actual marzo 2016. Valencia: Sociedad de Filosofía del País Valenciano.

Ruiz de Loizaga Martín, M. (2016). Crimen y castigo y Match Point. Más allá del azar. En Mundo Eslavo 15. Granada: Universidad de Granada.

Sanchez Noriega, J.L (2000). De la literatura al cine. Barcelona: Paidós.

Shakespeare, W. (1980). Hamlet / Macbeth. Barcelona: Editorial Planeta.

Sófocles (1992). Edipo en Colono. Madrid: Ediciones Clásicas. 
Steblin, R. (1995). Historia de la caracterización de las tonalidades en el siglo XVIII y comienzos del siglo XIX. En Quodlibet $n^{\circ} 33$ octubre 2005. Alcalá de Henares: Universidad de Alcalá.

Tchaikovsky, P.I. \& Shilovsky, K. (1993). Eugene Onegin. Londres: Richard Schauer Music Publishers.

Wilson, A. (2010). Beautiful shadow: A life of Patricia Highsmith. Londres: Bloomsbury Publishing Plc. 